to digest and rebuild the ECM. "There are not a lot of ways to study things that cells secrete into the matrix," says Leight, who works on matrix metalloproteinases (MMP), enzymes that cells secrete to degrade collagen during growth and tissue turnover.

Leight designed a peptide sensor, based on a collagen sequence cleaved by an MMP, that emits a fluorescent signal when the enzyme cuts it, and incorporated it into a hydrogel ${ }^{8}$. This allowed her to track the activity of the enzyme (see 'Enzyme activity in the matrix').

Similar sensors can be designed to study other secreted proteins, she says, and the reagents needed to make them are now available commercially. "It greatly reduces the barrier to more general use."

\section{UNDERSTANDING THE NUANCES}

But other obstacles remain. Although both synthetic and artificial materials are, in principle, easy to access, no common protocols exist to create these materials in a standardized way. Each lab has its own methods, so comparing data, even relating to the same tissue, is tricky.

Questions about how implanted materials assemble and degrade in vivo also linger. Segura, for example, can measure the polymer properties of the hydrogel injected into a mouse brain affected by a stroke. But because the dead tissue left behind after a stroke contains cell debris and various fluids, the hydrogel in the lab is "not at all what actually gets polymerized in vivo", Segura says. And it's impossible to visualize what happens in the depths of the brain. "We can only make sure that what we inject is the same every time."

When speaking to researchers starting out with ECMs, Gilbert says their most frequent question is 'what's the best biomaterial for my experiments?' There's no easy answer. 'You don't typically see side-by-side comparisons to be able to say, this is the advantage of this material over that one," she says, "That makes it hard to really home in on the best choice."

Nonetheless, says Christman, the pay-off is worth the effort. Any material, old or new, requires similar safety and standardization studies, she says, "I don't think people should feel discouraged or scared to design brand new materials and push them towards the clinic." -

Jyoti Madhusoodanan is a science writer in Portland, Oregon.

1. Safaee, H. et al. Cell. Mol. Bioeng. 10, 501-513 (2017).

2. Bissell, M. J., Hall, H. G. \& Parry, G. J. Theor. Biol. 99 31-68 (1982).

3. Crapo, P. M., Tottey, S., Slivka, P. F. \& Badylak, S. F. Tissue Eng. A 20, 313-323 (2014).

4. Trappmann, B. et al. Nature Commun. 8, 371 (2017).

5. Davoudi, S. et al. Biomaterials 173, 34-46 (2018).

6. Damaraju, S. M. et al. Biomaterials 149, 51-62 (2017).

7. Nih, L. R., Gojgini, S., Carmichael, S. T. \& Segura, T. Nature Mater. 17, 642-651 (2018).

8. Shin, D. S. et al. ACS Biomater. Sci. Eng. 4, 378-387 (2018).

\title{
The race for enzymatic DNA synthesis heats up
}

\section{An alternative to chemical oligonucleotide synthesis inches closer to reality.}

\section{BY JEFFREY M. PERKEL}

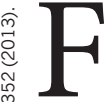
Tor decades, biologists have built custom DNA sequences chemically, from phosphoramidite building blocks that replicate natural bases. But the method is impractical beyond 200 bases, and environmentally hazard-

มู ous. New enzymatic strategies could circumvent those limitations.

In June 2018, George Church, a geneticist based at Harvard University in Cambridge, Massachusetts, and his colleagues reported encoding and decoding short messages in enzymatically synthesized DNA (H. H. Lee et al. Preprint at bioRxiv https://doi.org/c2cs; 2018); two months later, Molecular Assemblies, a biotechnology company in San Diego, California, announced a similar achievement.

In July, Sebastian Palluk and Daniel Arlow, in Jay Keasling's synthetic-biology laboratory at the University of California, Berkeley, published a strategy that they used to build ten-base oligonucleotides (S. Paluk et al. Nature Biotechnol. http://doi.org/gdqkff; 2018), and founded Ansa Biotechnologies to commercialize the approach.

And in October, DNA Script, based in Paris, announced that it had synthesized a 150-base DNA strand of defined sequence - an achievement that William Efcavitch, Molecular Assemblies' chief scientific officer, calls a "milestone". (At least two other companies also are pursuing

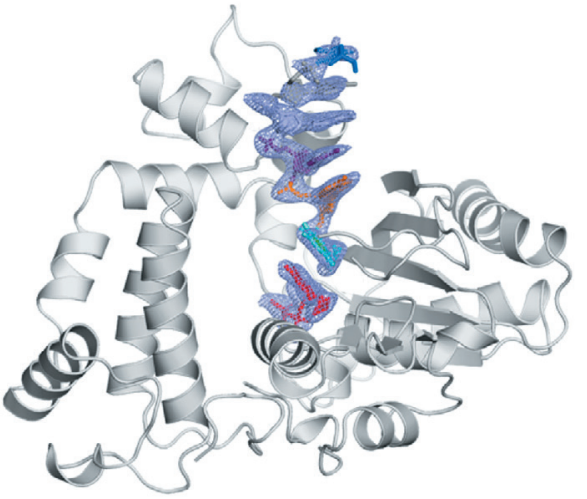

TdT, a template-independent DNA polymerase.

enzymatic strategies: Nuclera Nucleics and Evonetix, both based near Cambridge, UK.)

Key to enzymatic synthesis is terminal deoxynucleotidyl transferase (TdT), a DNA polymerase that requires no template. "It can add nucleotides without taking instructions," explains Marc Delarue, a structural biologist at the Pasteur Institute in Paris who collaborates with DNA Script. In theory, the approach can generate longer molecules than can chemical synthesis. It's also environmentally friendlier.

To control the sequence, developers must stop the enzyme after each step. Ansa tethers the nucleotide to the enzyme, thus physically blocking the DNA; others are developing TdT variants and modified DNA bases that act as reversible terminators. For DNA-based information storage, in which data are encoded in the transitions between bases rather than in their precise arrangement, the native enzyme and nucleotides can be used.

Enzyme-written DNAs are not yet commercially available. Nor can any published strategy rival chemical synthesis in length or efficiency. Palluk and Arlow reported $97.7 \%$ average coupling efficiency in their paper; Integrated DNA Technologies (IDT), a DNA-synthesis firm in Coralville, Iowa, touts $99.5 \%$. Yet less than $40 \%$ of molecules are correct at 200 bases; longer molecules would require higher efficiencies.

Still, says Emily Leproust, chief executive of the synthetic-DNA firm Twist Bioscience in San Francisco, California, "someone will crack it, and it's going to be great for the field". Adam Clore, technical director of synthetic biology at IDT, reckons that a "commercially viable product" is "probably several years off".

Those products could fill niches that chemistry cannot: long, complex sequences - synthetic gene libraries, for instance - for which assembly from shorter segments can add significant delays. "Any technology that can make that faster is going to be very valuable," says Christopher Voigt, a synthetic biologist at the Massachusetts Institute of Technology in Cambridge. "There is no Nobel prize that needs to happen," Leproust says. "It's just hard engineering." - 